\title{
MEDIA PEMBELAJARAN PEMANCAR WIRELESS FM MENGGUNAKAN RASPBERRY PI
}

\author{
Solekhan \\ Fakultas Teknik, Program Studi Teknik Elektro \\ Universitas Muria Kudus \\ Email: solekhan@umk.ac.id \\ Mohammad Iqbal \\ Fakultas Teknik, Program Studi Teknik Elektro \\ Universitas Muria Kudus \\ Email: mohammad.iqbal@umk.ac.id
}

\begin{abstract}
ABSTRAK
Media pembelajaran merupakan alat bantu yang diperlukan untuk menambah pemahaman dalam pembelajaran. Pemancaran gelombang FM, yang merupakan sebagian dalam Pengolahan Sinyal tanpa kabel, dibutuhkan dalam pemahaman pemancaran gelombang Radio. Raspberry Pi yang merupakan Single Board Computer, dapat diprogram dengan mudah dan memiliki keluwesan dalam penggunaannya. Dalam penelitian ini Raspberry dimanfaatkan penggunaannya sebagai pemancar FM. Proses pemancaran dilakukan dengan memanfaatkan Software Defined Radio. Dari hasil pengujian, pengubahan variasi frekuensi pemancaran FM dapat dilakukan dengan mudah, dan mampu memancarkan gelombang FM dengan baik.
\end{abstract}

Kata kunci: SBC; SDR; wireless FM.

\section{ABSTRACT}

Learning media are tools that are needed to increase understanding in learning. Transmission of FM waves, which is a part of wireless signal processing, is needed in understanding radio wave transmissions. Raspberry Pi, which is a Single Board Computer, can be programmed easily and has flexibility in its use. In this study Raspberry was used as an FM transmitter. The broadcasting process is carried out using Software Defined Radio. From the test results, changing the variation of FM transmitting frequency can be done easily, and is able to transmit FM waves properly.

Keywords: SBC; SDR; wireless FM.

\section{PENDAHULUAN}

Raspberry Pi, sering disingkat dengan nama Raspi, adalah komputer papan tunggal (Single-Board Circuit; SBC) yang seukuran dengan kartu kredit yang dapat digunakan untuk menjalankan program perkantoran, permainan komputer, dan sebagai pemutar media hingga video beresolusi tinggi. Raspberry Pi dikembangkan oleh yayasan nirlaba, Rasberry Pi Foundation, yang digawangi sejumlah pengembang dan ahli komputer dari Universitas Cambridge, Inggris.[1]

Seperti disebutkan dalam situs resmi Raspberry Pi Foundation, waktu itu Eben Upton, Rob Mullins, Jack Lang, dan Alan Mycroft, dari Laboratorium Komputer Universitas Cambridge memiliki kekhawatiran melihat kian turunnya keahlian dan jumlah siswa yang hendak belajar ilmu komputer. Mereka lantas mendirikan yayasan Raspberry Pi bersama dengan Pete Lomas dan David Braben pada 2009. Tiga tahun kemudian, Raspberry Pi Model B memasuki produksi massal. Dalam peluncuran pertamanya pada akhir Febuari 2012 dalam beberapa jam saja sudah terjual 100.000 unit. Pada bulan Februari 2016, Raspberry Pi Foundation mengumumkan bahwa mereka telah menjual 8 juta perangkat Raspi, sehingga menjadikannya sebagai perangkat paling laris di Inggris.[2].

Pemancar FM biasanya menggunakan perangkat elektronik sederhana seperti yang digunakan oleh João Dos Reis Tavares dan Heni Puspita [3], dimana untuk memancarkan gelombang radio FM memang digunakan secara elektronik.

Untuk beberapa keadaan maka hal tersebut bisa disederhanakan dengan menggunakan SDR. Software-Defined Radio (SDR) adalah merupakan sistem komunikasi radio dimana komponen yang biasa ada pada perangkat keras seperti mixer, filter, amplifier, modulator/demodulator dan detector digantikan dengan pengimplementasian perangkat lunak pada perangkat komputer atau embedded system.[5-12]

Beberapa penelitian [6,8] merupakan contoh penggunaan SDR untuk penelitian terkait dengan komunikasi radio. Namun dalam penelitian tersebut belumlah menunjukkan proses fleksibilitas 
pemanfaatan SDR sebagai radio berbasis software, sehingga pada penelitian ini akan disusun prototipe pemancar radio FM berbasis SDR dengan memanfaatkan Raspberry Pi. Pemilihan FM untuk dipancarkan, karena FM merupakan perangkat yang sangat populer.

Penelitian ini bertujuan untuk membuat prototipe pemancar Radio FM (Frequency Modulation) sebagai media pembelajaran pada laboratorium teknik elektro menggunakan Raspberry Pi.

Penelitian ini bermanfaat bagi kalangan akademisi dalam memecahkan masalah terkait pengolahan sinyal, selain itu juga hasil yang didapatkan dapat digunakan sebagai peraga kuliah pada mata pelajaran sistem pengolahan sinyal pada laboratorium teknik elektro.

\section{METODOLOGI PENELITIAN}

Raspberry Pi memiliki dua model: model A dan model B. Penyimpanan data tidak didesain untuk menggunakan cakram keras atau solid-state drive, melainkan mengandalkan kartu penyimpanan tipe SD untuk menjalankan sistem dan sebagai media penyimpanan jangka panjang.

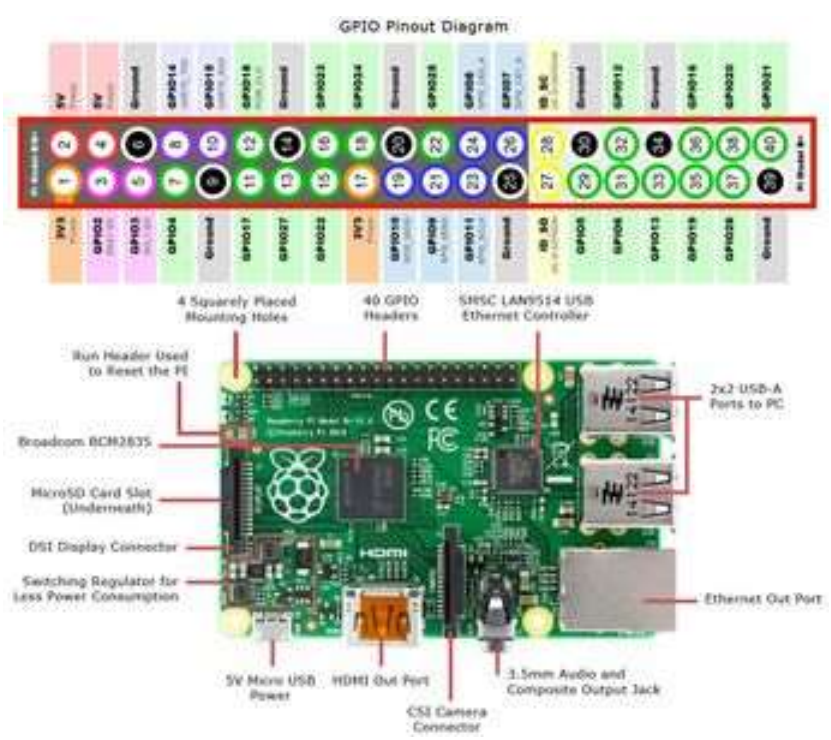

Gambar 1. Raspberry Pi

Pada Gambar 1. tersebut merupakan salah satu bentuk Raspberry Pi, dengan 40 pin. Raspberry Pi pada dasarnya merupakan Single Board Computer (SBC), sehingga bisa digunakan sebagai komputer secara mandiri dengan ditambahkan GPIO (General Purpose Input Output).

Sebagai SBC (Single Board Computer) yang mandiri, beberapa Sistem Operasi yang dapat dipasang pada Raspbery Pi diantaranya Raspbian, Pidora, OpenELEC, RaspBMC, OS RISC, Arch Linux, Windows 10. Sebagian besar sistem operasi pada Raspberry Pi adalah sistem operasi Linux [9], hal ini karena linux merupakan sistem operasi open source yang gratis untuk disebarluaskan di bawah lisensi GNU.

Python [10] sebagai bahasa pemrograman merupakan pilihan yang menarik, karena memiliki beberapa fitur diantaranya pustaka yang lengkap, mudah dipelajari, sintaks Python sederhana, modul numerik Python dengan komputasi yang efisien. Python merupakan bahasa pemrograman yang multiplatform sehingga bisa dijalankan pada banyak operating system.

Software yang digunakan untuk menghasilkan pemancar FM dengan menggunakan bahasa pemrograman python. Software ini dapat menghasilkan aplikasi yang dapat berjalan pada Raspberry Pi.

Untuk tahapan penelitian yang akan dilakukan untuk membuat pemancar FM dengan Raspberry pi yaitu : Pengumpulan Data, Perancangan Hardware, Perancangan Software, Pembuatan Hardware Software, Pengambilan Data, Analisa Data.

Hardware yang digunakan dibagi menjadi dua bagian yaitu pada sisi pemancar dan juga pada sisi penerima. Pada sisi pemancar hardware yang digunakan di antaranya adalah, Raspberry Pi, USB audio 3d, Kabel untuk antena, HDMI to VGA, Display, USB keyboard, USB mouse, dan Power supply 5V. Sedangkan pada sisi penerima hardware yang digunakan adalah, Radio penerima FM dan Komputer dengan USB RTL SDR.

Software yang digunakan dibagi menjadi dua bagian yaitu pada sisi pemancar dan juga pada sisi penerima. Pada sisi Pemancar untuk System yang digunakan adalah dengan menggunakan operating system raspbian OS yang berbasis linux debian. 


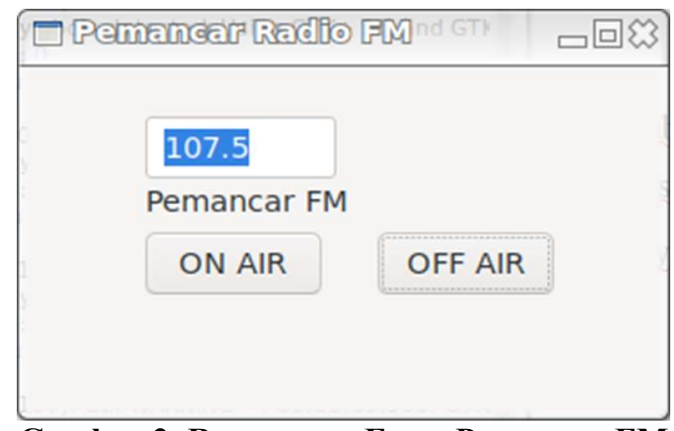

Gambar 2. Rancangan Form Pemancar FM

Sedangkan untuk pembuatan form digunakan programming berbahasa python dengan tampilan GUI digunakan wxpython. Untuk perencanaan menggunakan masukan dari frekuensi sehingga pada penelitian ini frekuensi digunakan sebagai input. Sedangkan output berupa sinyal radio FM, sehingga dibutuhkan tombol untuk mengeksekusi perintah untuk pemancar FM sesuai frekuensi masukkan. Hal ini dapat dilihat pada gambar 2. dari gambar tersebut apabila dilakukan pemasukan frekuensi maka akan muncul keterangan frekuensi yang dipancarkan.

Pada sisi penerima digunakan software GQRX dengan menggunakan USB SDR, dengan tujuan disamping mampu menerima suara radio FM, juga dapat menampilkan bentuk gelombangnya. Pada tahapan ini semua komponen pemancar dan penerima baik dari sisi hardware maupun software disusun, dengan pemancar FM diaktifkan, dan penerima FM juga diaktifkan.

\section{HASIL DAN PEMBAHASAN}

Agar Raspberry Pi dapat bertindak sebagai Pemancar FM didasari pemikiran bahwa sebagai SBC (Single Board Computer) Raspberry Pi memiliki sistem digital sinkron yang terkait dengannya yang digunakan untuk mengurangi interferensi elektromagnetik. Penindasan EMI ini dilakukan oleh sinyal yang disebut Spread-spectrum clock signal atau SSCS.

Frekuensi sinyal ini dapat bervariasi dari $1 \mathrm{MHz}$ hingga $250 \mathrm{MHz}$, hal ini dapat dimanfaatkan sebagai pemancar karena masuk didalam pita gelombang radio FM. Jadi dengan menulis kode untuk melakukan modulasi frekuensi menggunakan sinyal clock spread-spectrum akan dapat mengubah Pi bekerja sebagai pemancar FM. Sinyal termodulasi akan diberikan melalui pin 4 GPIO dari Raspberry Pi, dengan memasang kabel normal maksimum $20 \mathrm{~cm}$ ke pin 4 GPIO tersebut sebagai antena.

Pemancar FM ini akan bekerja dari sekitar 1Mhz hingga 250Mhz, di sebagian besar negara band FM yang digunakan antara $88 \mathrm{Mhz}$ hingga $108 \mathrm{Mhz}$. Sebagian besar penerima radio menginginkan sinyal kelipatan $0,1 \mathrm{MHz}$ agar bekerja dengan baik.

Semua pemancar lebih dari $500 \mathrm{~mW}$ memerlukan lisensi. Berapa daya output Raspberry Pi (dalam $\mathrm{mW}$ ), gelombang kotak yang berasal dari pin GPIO, adalah gelombang sinus, dan pada saat yang sama menganggap antena digerakkan secara langsung. Dengan mengingat bahwa output tegangan maksimum dari Raspberry Pi 3.3 Volt, arus maksimum GPIO adalah $16 \mathrm{~mA}$.

Untuk memperhitungkan daya yang dipancarkan dapat dihitung dengan menggunakan persamaan seperti berikut:

$$
\begin{aligned}
& \text { Pavg }=\text { Vrms } \cdot I m a x \\
& \text { Vrms }=\frac{V p p}{\sqrt{2}} \\
& \text { Pavg }=3,3 \cdot 0,707 \cdot 0,00016=0,37 \mathrm{~W}
\end{aligned}
$$

Dengan : Pavg merupakan Daya rata-rata, Vrms adalah Tegangan rms, Imax merupakan Arus Maksimal, dan Vpp adalah merupakan Tegangan peak-to-peak. Pada persamaan (1) hingga (3) terlihat daya yang dihasilkan masih dalam taraf yang kurang dari $500 \mathrm{~mW}$, sehingga tidak diperlukan untuk perijinan.

Untuk memperkuat daya pemancar FM maka harus melakukan perijinan pada instansi terkait dan menambah peralatan peralatan khusus untuk penguat pemancar. Pada penelitian ini pemancaran FM hanya bersifat sementara dan dalam skala laboratorium, serta tidak dikuatkan, hanya sebagai media pembelajaran saja. Untuk pengaturan frekuensi pancar dilakukan dengan mengubah melalui form pemancar yang dibuat. Untuk pengujian form dapat dilihat pada Gambar 3. 


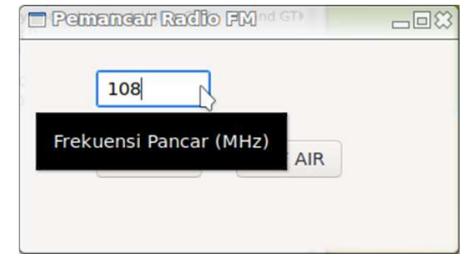

(a)

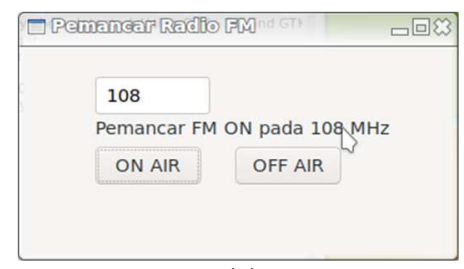

(c)

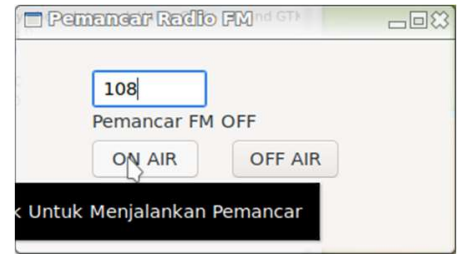

(b)

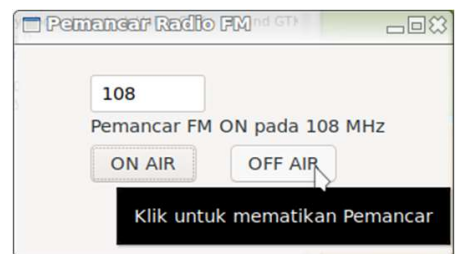

(d)

Keterangan :

(a) Pengisian frekuensi pemancar FM (misal 108Mhz)

(b) Klik ON AIR untuk menghidupkan pemancar FM

(c) Tampilan keterangan frekuensi pemancar FM

(d) Klik OF AIR untuk mematikan pemancar FM

\section{Gambar 3. Form Pemancar FM dengan Raspberry Pi}

Dari perancangan seluruh sistem yang terdiri dari sistem hardware dan software, untuk menghasilkan sistem pemancar FM, prototipe pemancar dapat dilihat pada Gambar 4.

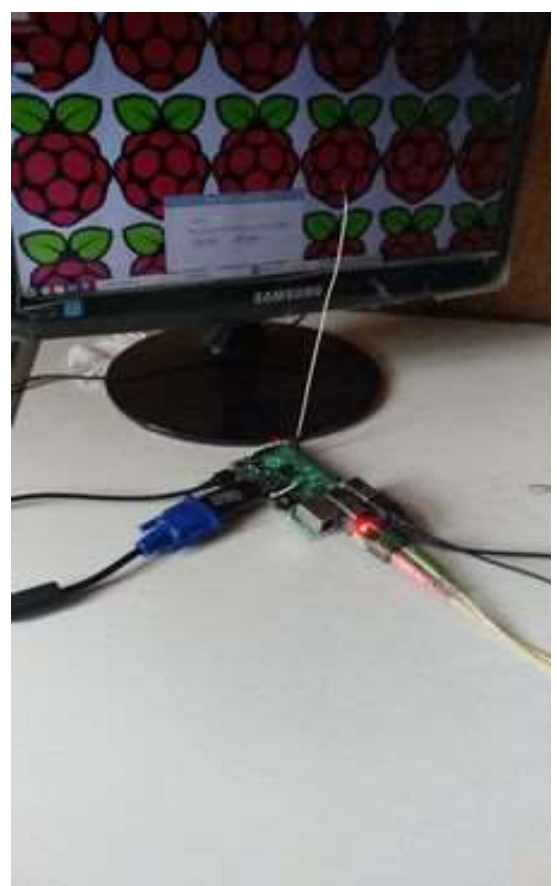

\section{Gambar 4. Hasil Pemancar FM dengan Raspberry Pi}

Dari Gambar 4. tersebut merupakan Raspberry Pi yang dihubungkan ke display melalui HDMI, dan untuk input suara dimasukkan melalui USB 3Dsound. 


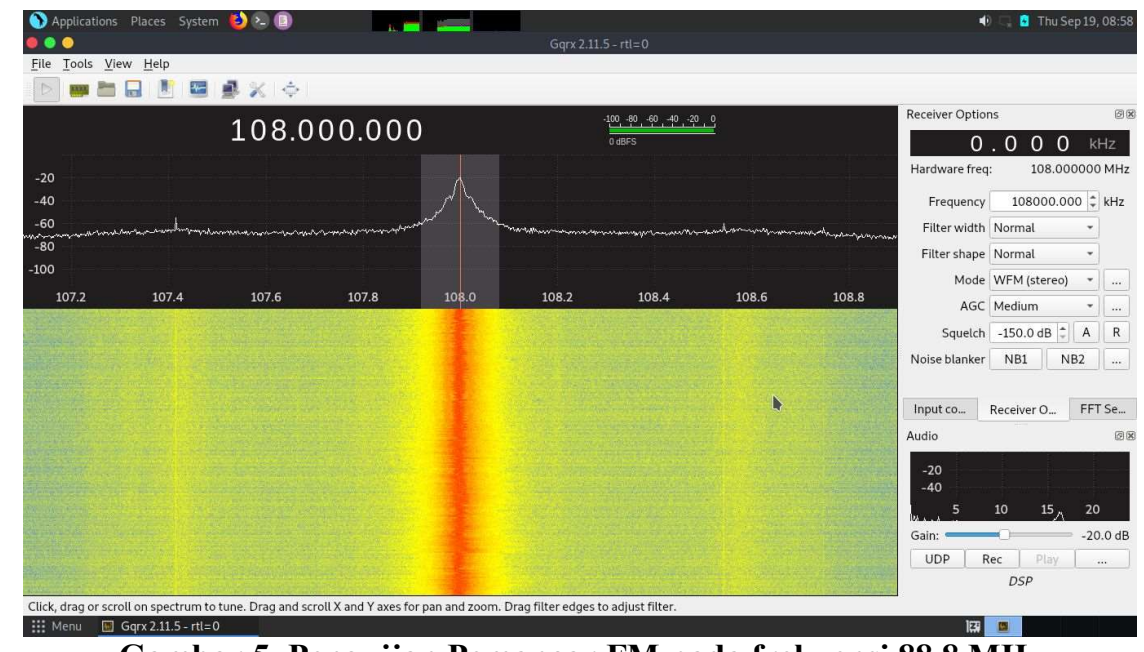

Gambar 5. Pengujian Pemancar FM pada frekuensi 88.8 MHz

Pada Gambar 5. merupakan tampilan pada area disekitar $88.8 \mathrm{MHz}$ setelah pemancar FM dihidupkan, terlihat adanya lonjakan magnitude pada area frekuensi pemancar tersebut. Dengan menggunakan cara yang sama pengujian untuk frekuensi lainnya dapat di tuliskan pada tabel berikut :

Tabel 1. Pengujian berbagai variasi frekuensi pemancar FM

\begin{tabular}{ccc}
\hline No & Frekuensi Pemancar $(\mathbf{M H z})$ & Ket \\
\hline 1 & 60 & Bisa \\
2 & 77 & Bisa \\
3 & 88.8 & Bisa \\
4 & 90 & Bisa \\
5 & 100 & Bisa \\
6 & 108 & Bisa \\
7 & 109 & Bisa \\
8 & 150 & Bisa \\
9 & 200 & Bisa \\
10 & 230 & Bisa \\
11 & 240 & Bisa \\
12 & 245 & Bisa \\
13 & 249 & Bisa \\
\hline
\end{tabular}

Pemancar FM dapat memancarkan gelombang FM dengan berbagai variasi frekuensi. Pada frekuensi yang rendah terlihat tanggapan bandwidthnya menyempit, sedangkan pada frekuensi semakin naik bandwidth melebar. Karena untuk Radio FM tanggapan frekuensinya antara 88MHz hingga 108MHz, maka dari pengujian, alat ini dapat digunakan sebagai pemancar Radio FM.

\section{KESIMPULAN}

Berdasarkan metodologi penelitian serta hasil dan pembahasan pada bagian sebelumnya, dapat disimpulkan bahwa:

a) Telah dibuat prototipe pemancar FM dengan menggunakan Raspberry Pi.

b) Pemancar dapat memancarkan frekuensi pancar sesuai dengan range frekuensi radio FM dari $88-108$ Mhz. berikut:

Sebagai saran untuk rekomendasi yang dapat disampaikan dari hasil penelitian ini adalah sebagai 
a) Jika dikehendaki pemancar mampu memancarkan dibawah $88 \mathrm{Mhz}$ ataupun diatas $108 \mathrm{Mhz}$ (1- 250 $\mathrm{MHz}$ )

b) Untuk meningkatkan daya pemancar dibutuhkan perijinan untuk penggunaan frekuensi pada instansi terkait, dan juga penguat pemancar.

\section{DAFTAR PUSTAKA}

[1] Blanchette, Megan. 2015. 4 ways the Raspberry Pi is being used in education. O'Reilly Radar.

[2] Hern, Alex. "Raspberry Pi 3: the credit card-sized 1.2 GHz PC that costs \$35". The Guardian.

[3] João Dos Reis Tavares, Heni Puspita. 2016. Pembuatan Pemancar FM Sederhana Untuk Alat Peraga. INDEPT, Vol. 6, No. 1 Februari ISSN:2087 - 9245

[4] Lb Nugroho. 2017. Analisa Pemanfaatan Frekuensi Radio FM (Frequency Modulation) Untuk Telekomunikasi Bawah Air

[5] Markus Dillinger, Kambiz Madani, Nancy Alonistioti. 2003. Software defined radio: architectures, systems and functions, page xxxiii (wiley \& sons, ISBN 0-470-85164-3)

[6] Ida Anisah1, Hendy Briantoro, Ahmad Zainudin, Desy Intan Permatasari. 2018. Implementasi Sistem Komunikasi Nirkabel Ofdm Berbasis Software Defined Radio (SDR), JNTETI, Vol. 7, No. 2, Mei 2018 183

[7] Eko Marpanaji, Kadarisman Tejo Yuwono, Adi Dewanto. 2012. Aplikasi Platform Komputasi Software-Defined Radio (SDR) Untuk Digital Spectrum Analizer, Prosiding Pertemuan Ilmiah XXV Hfi Jateng \& DIY

[8] Sotyohadi, Sulistiawati, Irrine Budi. 2019. Desain Low Noise Transceiver 7 Mhz Berbasis Software Defined Radio (SDR). Jurnal MNEMONIC, [S.1.], V. 2, N. 1, P. 73 - 78. Jan. 2019. ISSN 2614-4808.

[9] Lumma, Carl. 2007. Linux: It's Not Just For Computer Geeks Anymore. Keyboard Magazine. New Bay Media, LLC.

[10] Guttag, John V. 2016. Introduction to Computation and Programming Using Python: With Application to Understanding Data. MIT Press. ISBN 978-0-262-52962-4.

[11]Di Pu, Alexander M. Wyglinski. 2013. Digital Communication Systems Engineering with SoftwareDefined Radio. Artech House. ISBN: 1608075257,9781608075256. 